\title{
Temporary iatrogenic fetal tricuspid valve atresia in a case of twin to twin transfusion syndrome
}

\author{
Kurt Hecher, Ian D Sullivan, Kypros H Nicolaides
}

Harris Birthright Research Centre for Fetal Medicine, King's College Hospital Medical School, London

K Hecher

K H Nicolaides

Cardiothoracic Unit, The Hospital for Sick Children, London I D Sullivan

Correspondence to:

Dr Kurt Hecher,

Department of Obstetrics and Gynaecology,

Landeskrankenhaus, $\mathrm{St}$

Veiterstrasse 47, A-9020

Klagenfurt, Austria.

Accepted for publication 16 May 1994

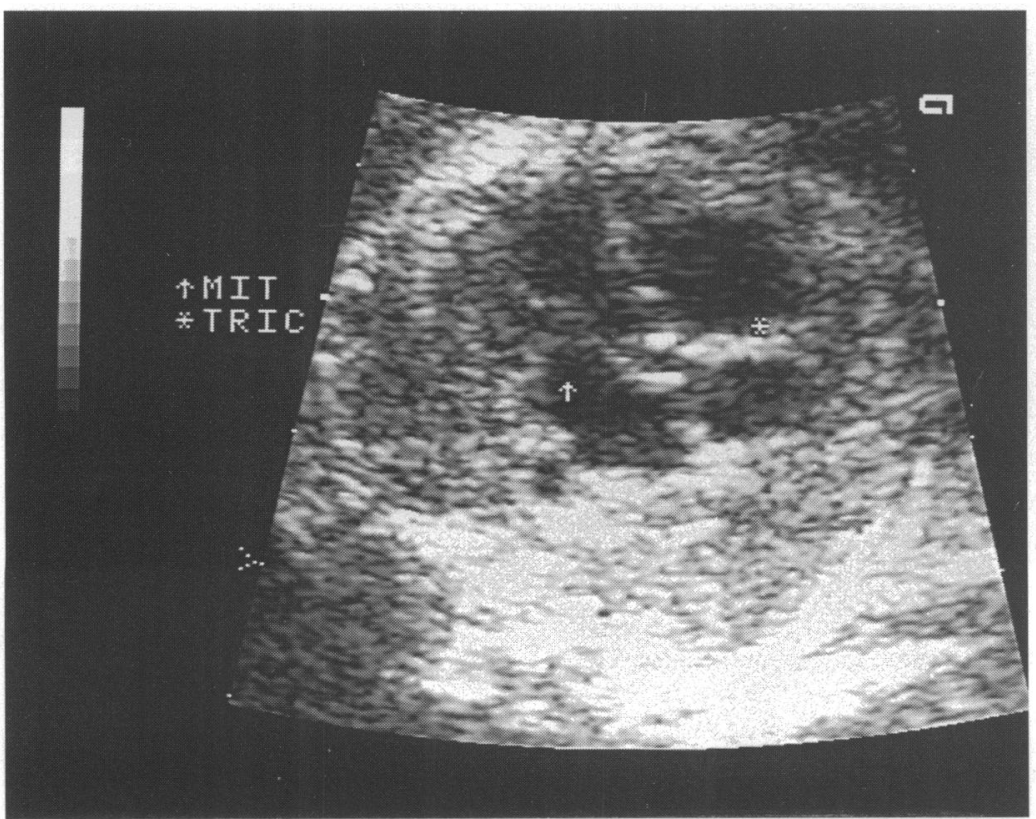

Figure 1 Four chamber view of the fetal heart. The tricuspid valve (*) was closed, whereas the mitral valve opened during diastole. MIT, mitral valve, TRIC, tricuspid valve.

(Br Heart f 1994;72:457-460)

Almost all monochorionic twin pregnancies have communicating placental vessels between the umbilical cord insertions. Where there are artery to vein anastomoses a chronic shunt of blood from one fetus to the other can

\begin{abstract}
This report describes the sequence of events in the development and subsequent spontaneous resolution of functional tricuspid valve atresia in the donor fetus in a case of twin to twin transfusion syndrome. Fetoscopic laser coagulation of the placental anastomoses was performed at 20 weeks' gestation. Subsequently, there was evidence of increased placental vascular resistance in the donor twin and major impairment of right ventricular function with no forward flow through the tricuspid valve. During the next four weeks, however, there was spontaneous and complete recovery of ventricular function and resolution of the functional tricuspid valve atresia. These findings suggest that alterations in fetal haemodynamics may result in structural cardiac abnormality and may be the precursors of some forms of congenital heart disease.
\end{abstract} showed high placental resistance in the donor, with a pulsatility index (PI) of 1.65 , whereas the PI was normal $(0.99)$ in the recipient. Both fetuses had normal waveforms in the descending thoracic aorta. The recipient showed mild tricuspid regurgitation. Under local anaesthesia the communicating vessels on the chorionic placental surface were coagulated by fetoscopically directed (through a $2 \cdot 7$ $\mathrm{mm}$ diameter cannula) neodynium yttrium aluminium garnet laser. ${ }^{2}$

At 21 weeks' gestation, ultrasound examination showed a normal amount of amniotic fluid in both sacs. However, the donor, still identifiable by its smallness, had a pericardial effusion. Doppler studies showed increase in umbilical artery PI in both fetuses (recipient 1.44; donor 2.08).

At 22 weeks' gestation, echocardiography of the donor fetus showed biventricular enlargement and a hyperechogenic tricuspid valve that did not open during diastole (fig 1). 


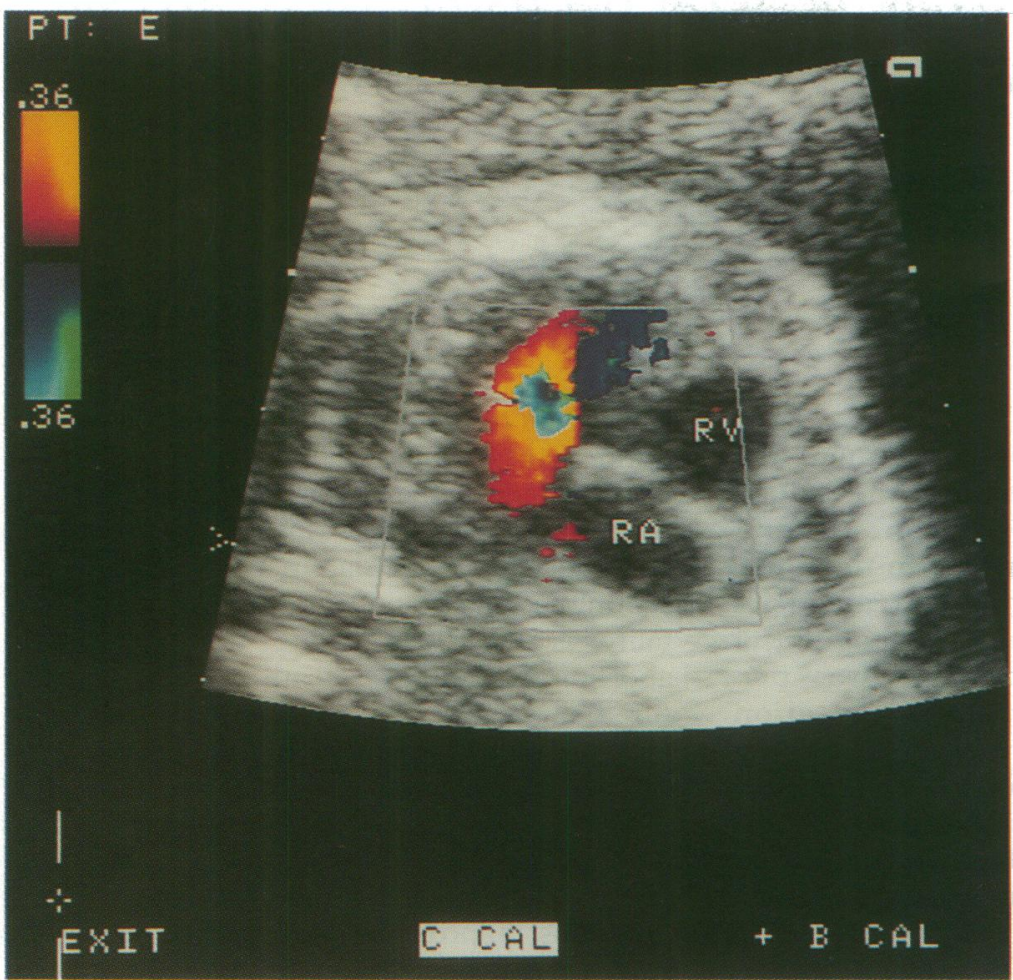

Figure 2 Colour Doppler imaging of left ventricular inflow. There was no blood flow from the right atrium $(R A)$ to the right ventricle $(R V)$ during diastole.

Figure 3 Pulsed Doppler investigation of blood flow at the level of the

pulmonary valve showing pulmonary incompetence with retrograde filling of the right ventricle.
Colour Doppler showed no tricuspid atrioventricular diastolic inflow or systolic regurgitation (fig 2). The right ventricle was filled by retrograde diastolic blood flow in the ductus arteriosus and pulmonary trunk through an incompetent pulmonary valve (fig 3 ). In both the descending thoracic aorta $(\mathrm{PI}=3.34)$ and umbilical artery $(\mathrm{PI}=3 \cdot 13)$ there was reversed diastolic flow indicating very high placental resistance. Venous blood flow stud- ies showed reversed velocities in the ductus venosus during atrial contraction, which is never seen in normal fetuses (fig 4). ${ }^{3}$ In the former recipient fetus, echocardiography showed normal findings and the PIs in the umbilical artery $(1 \cdot 16)$ and thoracic aorta $(2 \cdot 11)$ were within the normal ranges for gestation.

At 24 weeks' gestation there was intermittent tricuspid regurgitation (fig 5) and at 25 weeks there was transtricuspid right ventricular filling combined with pansystolic regurgitation (fig 6). There was still reversed diastolic flow in the umbilical artery and no end diastolic flow in the thoracic aorta.

At 31 weeks' gestation the cardiac abnormalities had completely resolved. There was normal opening of the tricuspid valve and right ventricular filling and no systolic regurgitation. End diastolic flow in the umbilical artery had changed from reversed to absent and in the thoracic aorta it was positive.

At 33 weeks' gestation there was spontaneous rupture of the membranes and two girls were delivered by caesarean section. The birthweights of the former recipient and donor twins were $2100 \mathrm{~g}$ and $1500 \mathrm{~g}$ respectively and they both had an uneventful postnatal course. When they were a week old, echocardiography of the smaller baby showed mild hypoplasia of the right ventricular cavity but the tricuspid valve was morphologically normal. There was normal ventricular filling without tricuspid regurgitation or pulmonary incompetence. When they were two months old right ventricular growth was normal and the tricuspid annulus was $10 \mathrm{~mm}$ in the smaller baby. However, there was a small atrial septal defect with pure left to right shunt. The bigger baby (former recipient) had a small atrial septal defect and mild pulmonary stenosis.

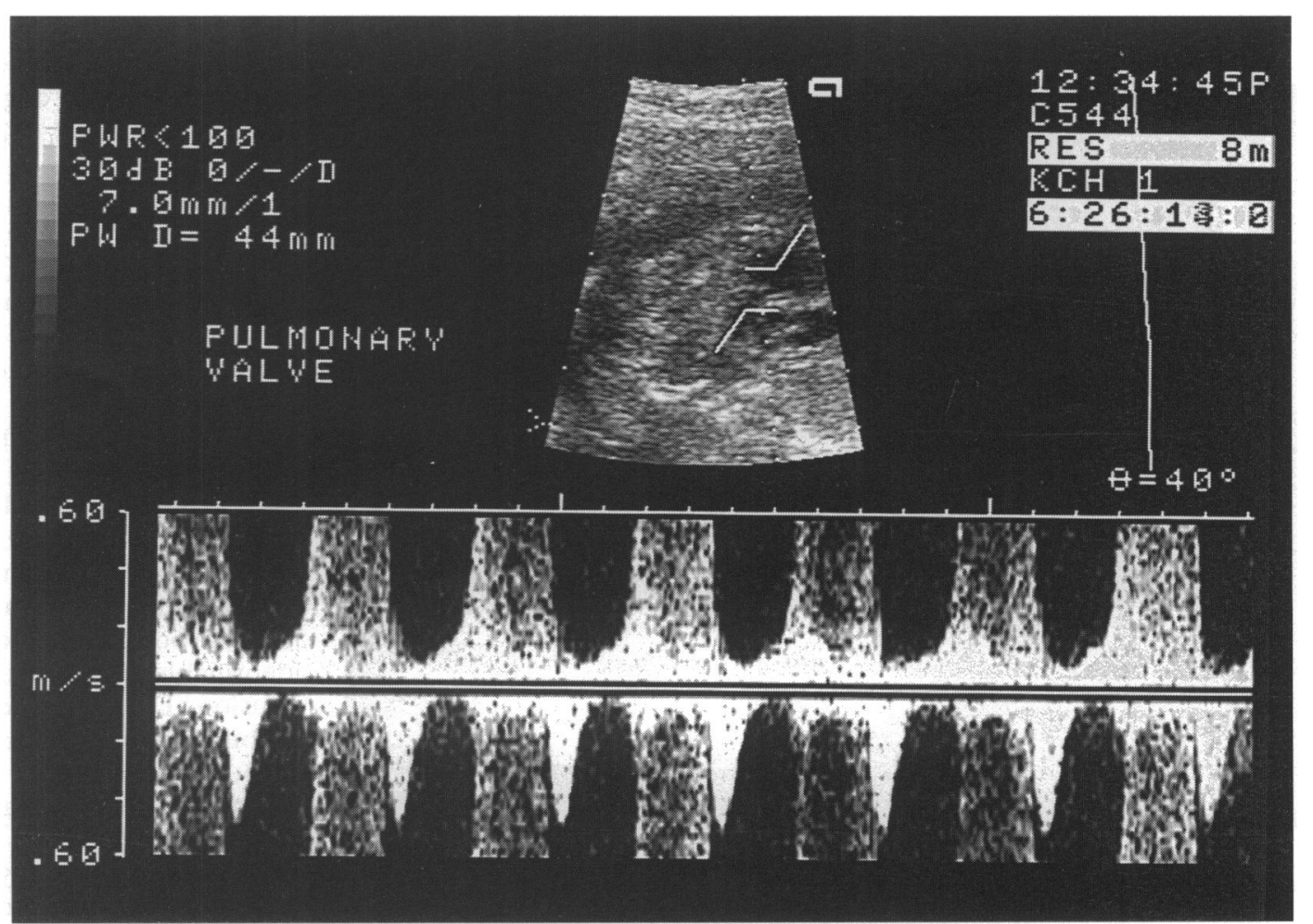


Figure 4 Comparison of blood flow velocity waveforms of the ductus venosus (left) and hepatic veins (right) in both twins. The upper panel shows waveforms of the former donor which are severely abnormal. Note the marked reversal of blood flow in the ductus venosus during atrial contraction. The waveform of the hepatic vein has no second peak of forward flow during early diastole but there is also increased retrograde blood flow during atrial contraction. The lower panel shows normal waveforms of the former recipient. Ductus venosus blood flow is directed toward the heart throughout the whole hear cycle and the hepatic vein waveform has the typical triphasic shape with moderate reversal of flow during atrial contraction.

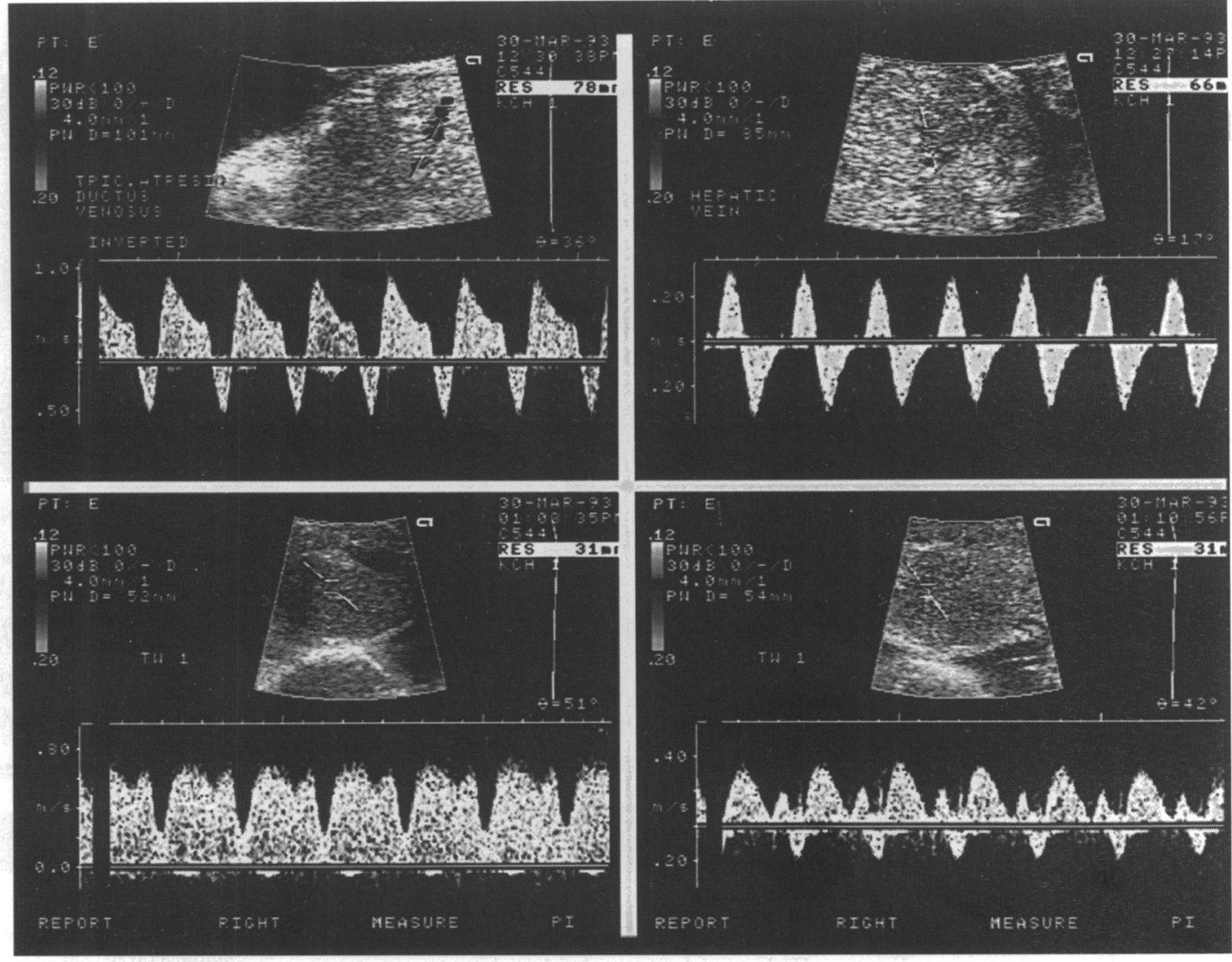

\section{Discussion}

Laser coagulation of the placental anastomoses was associated with a major increase in resistance to flow from the donor fetus into the placenta, as shown by reversal of diastolic blood flow velocities in the umbilical arteries

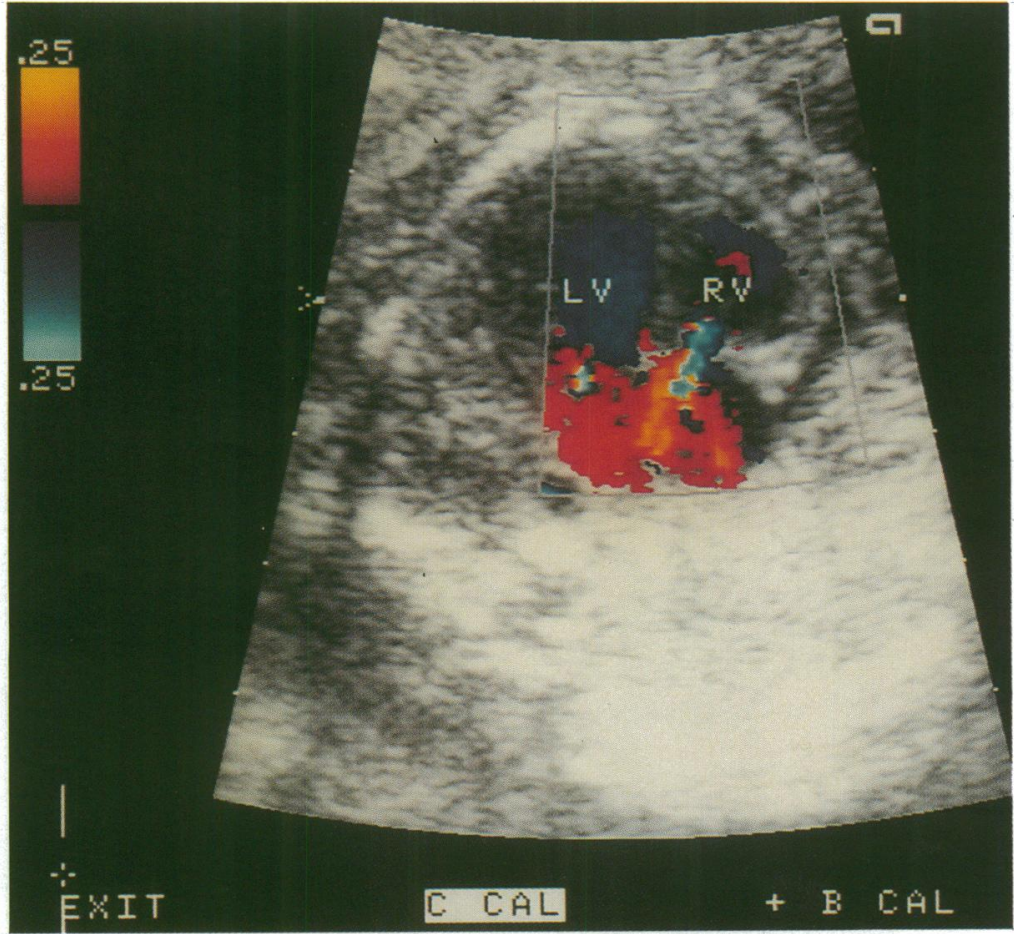

Figure 5 Colour flow mapping of intracardiac blood flow showing tricuspid regurgitation (blue). $R V$, right ventricle; LV, left ventricle. and the descending thoracic aorta. Consequently, there was severe impairment of right ventricular function, presumably because the right ventricular afterload was increased. Right ventricular function was compromised to such an extent that there was no forward flow through the tricuspid valve and no discernible right ventricular myocardial contraction. The tricuspid valve was functionally atretic and stationary in a closed position. The abnormal venous waveforms, with marked reversed flow during atrial contraction, are the consequence of the cardiac findings.

During the subsequent weeks there was improvement in the flow velocity waveforms in the umbilical artery, from reversal to absence of diastolic velocities, and this was associated with recovery of cardiac function. The postnatal finding of a smaller than usual right ventricular cavity is consistent with a period of prenatal arrested growth with subsequent recovery. The apparently complete recovery of ventricular function shows that even severely compromised function may be reversible if the abnormality in cardiac loading resolves.

The mild pulmonary valve stenosis present postnatally in the recipient twin is the only apparent residual cardiac abnormality after the prenatal compromise of right ventricular performance that was part of the natural history of the syndrome. The cardiac abnormalities in the donor twin were an unintended consequence of treatment.

The sequence of events suggests that alterations in fetal haemodynamics may result in structural cardiac abnormality and may be the 
Figure 6 Pulsed Doppler investigation of blood flow through the tricuspid valve. After diastolic inflow ( $E$ and $A$ wave) there is pansystolic regurgitation. $R A$, right atrium; $R V$, right ventricle.

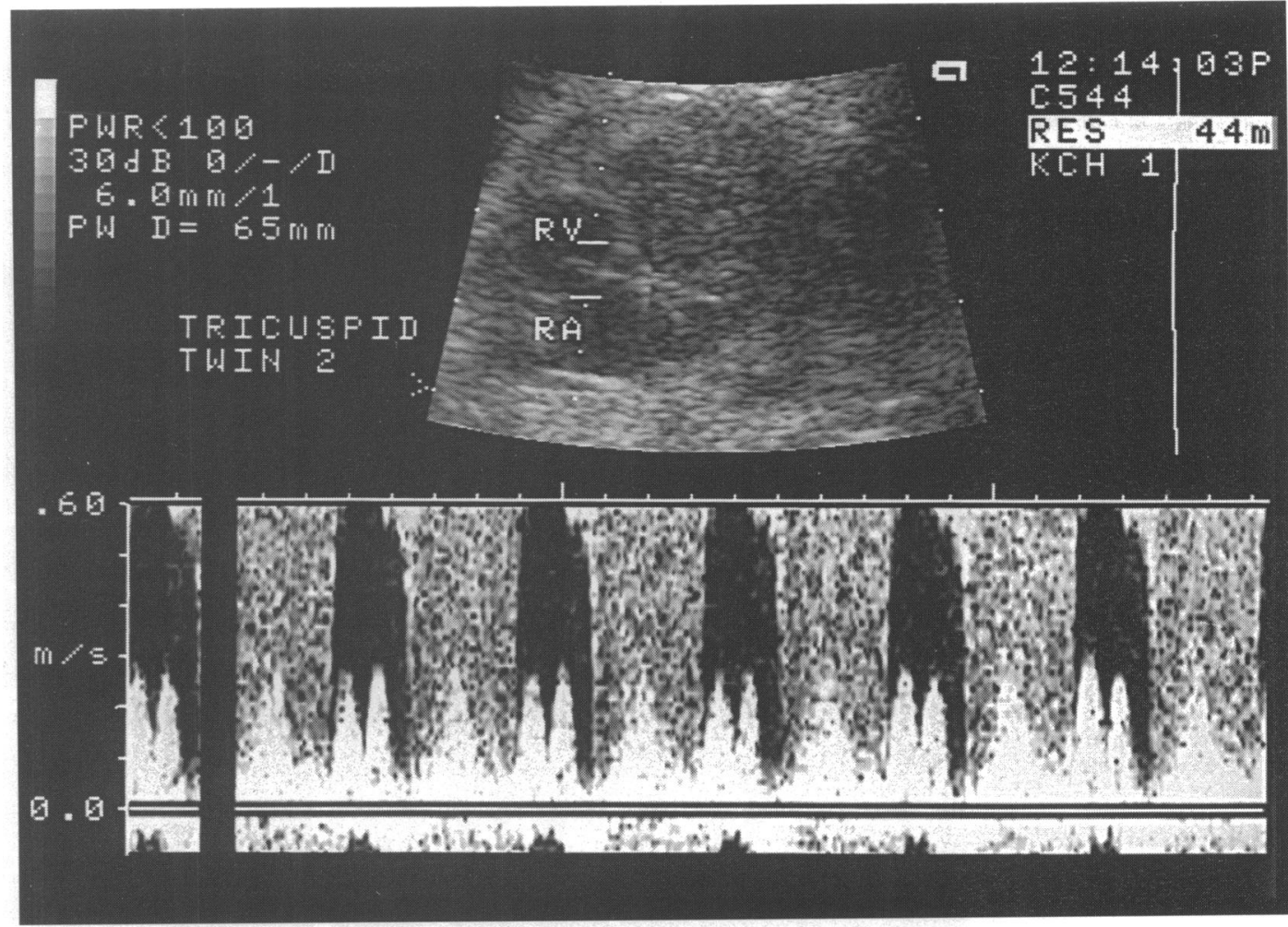

precursor of some forms of congenital heart disease. Tricuspid regurgitation is a common prenatal abnormality, ${ }^{4}$ whereas isolated tricuspid regurgitation is uncommon postnatally, ${ }^{5}$ because most cases recognised prenatally are lethal. It seems likely that the most common cause is increased right ventricular afterload. It has long been suggested that abnormalities in fetal flow patterns may be implicated in some forms of structural congenital heart disease, ${ }^{6}$ and this case report provides objective support for this hypothesis.

$\mathrm{K} \mathrm{H}$ was supported by a grant (J628-MED) from the Austrian Science Foundation.
1 Saunders NJ, Snijders RJM, Nicolaides KH. Therapeutic amniocentesis in twin-twin transfusion syndrome appearing in the second trimester of pregnancy. $A m$ Obstet Gynecol 1992;166:820-4.

2 Ville $Y$, Hecher $K$, Ogg $D$, Warren $R$, Nicolaides $K$. Successful outcome after Nd:YAG laser separation of Ultrasound Obstet Gynecol 1992;2:429-31. Reference ranges for fetal venous and intracardiac blood flow parameters. Ultrasound Obstet Gynecol 1994;4:(in press)

4 Allan LD. Diagnosis of fetal cardiac abnormalities. Arch Dis Child 1989;64:964-8.

5 Cullen S, Sharland G, Allan LD, Sullivan ID. Potential impact of population screening for prenatal diagnosis of congenital heart disease. Arch Dis Child 1992;67: $775-8$.

6 Shinebourne EA, Elseed AM. Relation between fetal flow patterns, coarctation of the aorta, and pulmonary blood flow. Br Heart $¥$ 1974; 36:492-8. Successful outcome after

3 Hecher $K$ Snijders $R$, Campbell $S$, Nicolaides $K$ 